\title{
The effectiveness of more advanced human resource systems in small firms
}

Citation for published version (APA):

de Grip, A., \& Sieben, I. J. P. (2009). The effectiveness of more advanced human resource systems in small firms. International Journal of Human Resource Management, 20(9), 1914-1928.

https://doi.org/10.1080/09585190903142373

Document status and date:

Published: 01/01/2009

DOI:

10.1080/09585190903142373

Document Version:

Publisher's PDF, also known as Version of record

Document license:

Taverne

Please check the document version of this publication:

- A submitted manuscript is the version of the article upon submission and before peer-review. There can be important differences between the submitted version and the official published version of record.

People interested in the research are advised to contact the author for the final version of the publication, or visit the DOI to the publisher's website.

- The final author version and the galley proof are versions of the publication after peer review.

- The final published version features the final layout of the paper including the volume, issue and page numbers.

Link to publication

\footnotetext{
General rights Owners
rights.

- You may freely distribute the URL identifying the publication in the public portal. please follow below link for the End User Agreement:

www.umlib.nl/taverne-license

Take down policy

If you believe that this document breaches copyright please contact us at:

repository@maastrichtuniversity.nl

providing details and we will investigate your claim.
}

Copyright and moral rights for the publications made accessible in the public portal are retained by the authors and/or other copyright owners and it is a condition of accessing publications that users recognise and abide by the legal requirements associated with these

- Users may download and print one copy of any publication from the public portal for the purpose of private study or research.

- You may not further distribute the material or use it for any profit-making activity or commercial gain

If the publication is distributed under the terms of Article $25 \mathrm{fa}$ of the Dutch Copyright Act, indicated by the "Taverne" license above, 


\section{The effectiveness of more advanced human resource systems in small firms}

\section{Andries De Grip \& Inge Sieben}

To cite this article: Andries De Grip \& Inge Sieben (2009) The effectiveness of more advanced human resource systems in small firms, The International Journal of Human Resource Management, 20:9, 1914-1928, DOI: 10.1080/09585190903142373

To link to this article: https://doi.org/10.1080/09585190903142373

$$
\text { 曲 Published online: } 23 \text { Sep } 2009 .
$$

Submit your article to this journal ¿

$$
\text { Џ Article views: } 502
$$

Q View related articles $₫$

4 Citing articles: 7 View citing articles 진 


\title{
The effectiveness of more advanced human resource systems in small firms
}

\author{
Andries De Grip ${ }^{\mathrm{a}}$ and Inge Sieben ${ }^{\mathrm{b}}$ \\ ${ }^{a}$ Research Centre for Education and the Labour Market (ROA), Maastricht University, Maastricht, \\ the Netherlands; ${ }^{b}$ Department of Sociology, Tilburg University, the Netherlands
}

\begin{abstract}
In this paper, we analyze whether Human Resource (HR) systems in small firms can be associated with higher performance as well as higher wages. Our study, which focuses on Dutch pharmacies, shows that more advanced HR systems do not have any effect on firms' productivity. In these micro firms, it is only employees who significantly benefit from the introduction of both a basic and a more advanced HR system. Our findings that small firms do not significantly benefit from introducing less traditional HR practices offer an explanation for the thresholds in the diffusion of these HR practices in small firms, and suggest that in these firms formal HR practices are less important than personal relations between the employer and his or her employees.
\end{abstract}

Keywords: firm performance; HRM; human capital; pharmacies; small firms; wages

\section{Introduction}

From the beginning of the 1990s onwards, many studies have focused on the effects of human resource (HR) practices on firm performance. Several studies showed that in large firms a more advanced HR system is associated with a better performance (e.g. Ichniowski, Shaw and Prennushi 1997). One might, however, wonder whether this applies to small or micro firms as well. For instance, it will be difficult to copy more advanced HR systems in which employees work in autonomously operating teams, when the entrepreneur is usually present on the shop floor. This might explain why small firms often have less formal HR practices than large firms (Hornsby and Kuratko 1990; Bacon and Hoque 2005). In addition, small firms might pursue other business strategies than larger firms, which make the need for more advanced HR systems less urgent. Moreover, small firms might have a lack of HR expertise, and are often badly informed on the possible impact of HR practices, because they lack professional HR staff (De Kok and Uhlaner 2001).

Until now, there have been only a few studies that focus on HR practices in small firms (Way 2002; Batt 2002; Chandler and McEvoy 2000; Faems, Sels, De Winne and Maes 2005; De Grip and Sieben 2005; Zheng, Morrison and O'Neill 2006; Sels et al. 2006). In this paper, we want to contribute to this literature by analyzing whether, in micro firms, employers as well as employees benefit from the introduction of a more advanced HR system.

From the literature on technology diffusion (e.g. Geroski 2000), we know that firm size may have large effects on the benefits of the introduction of new technologies. There often are thresholds below which savings in wage costs do not exceed the costs of a new machine. We expect that this also holds for the introduction of more advanced HR systems. In small firms, the benefits of these systems may not outweigh the higher wage costs as small firms do

\footnotetext{
*Corresponding author. Email: a.degrip@maastrichtuniversity.nl
} 
not benefit from the advantages of delayering the organization, introducing self-responsible teams, and higher sales, as much as large firms do (cf. Way 2002).

We focus our study on the effects of consistent HR systems in small firms, ranging from traditional workplace relations without any explicit HR practices, to more advanced HR systems, which we label 'High Quality' systems. Firms that apply the latter HR system focus on recruiting and developing a very competent workforce (cf. Heneman, Tansky and Camp 2000). We will analyze whether these more advanced HR systems are associated with both higher levels of productivity and higher wages, i.e. whether a more advanced HR system creates a 'mutual gain enterprise' for both employer and employees (Handel and Levine 2004).

We conduct our analyses on a unique, matched employer-employee data set from Dutch pharmacies. This data set was also used by De Grip and Sieben (2005), who analyzed the effects of miscellaneous HR practices on pharmacies' productivity and employees' wages. However, their analysis did not look at the internal fit of various HR practices, or at the impact of more coherent HR 'systems' (cf. Arthur 1994). As is often argued, the HR system approach is more adequate in analyzing effects of human resource management, because several practices turn out to be strongly correlated (e.g. Wood 1999). Moreover, Milgrom and Roberts (1995) stated that doing more of a particular HR practice increases the returns of doing additional practices.

The sector approach we follow in this paper is highly appropriate for research on the effects of HR systems, because it allows us to apply an 'insider econometrics' approach (Ichniowski and Shaw 2003), which includes a detailed knowledge of the nature of work and the actual HR systems used in a particular sector of industry. Moreover, this sector approach enables us to use physical measures of productivity that are more straightforward in measuring productivity than financial measures are (Ichniowski et al. 1997).

We will focus our analysis on the 'core' workers (Osterman 1994) of Dutch pharmacies 'pharmacist's assistants' - who have to meet high professional standards. This makes the pharmacy sector in the Netherlands a highly interesting sector in which to analyze the impact of a High Quality HR system. We use the term High Quality HR system instead of the more often used 'High Performance Workplace' or 'High Involvement Management' (Wood 1999) because the latter concepts often include HR practices, such as job rotation, self-responsible teams, or quality circles, which are not relevant in small firms, where the entrepreneur has the lead on the work floor. Moreover, the term 'High Quality' reflects the dominant focus of human resource management in Dutch pharmacies. Most HR practices in these pharmacies focus on improving the quality of the workforce, for instance by employing a highly competent workforce, schooling and coaching, evaluating performance, allowing assistants to perform tasks of the pharmacist, and employing workers with a permanent contract.

It should be noted that pharmacies in the Netherlands have to deal with all kinds of regulations, but nevertheless are truly independent, for-profit firms. Dutch pharmacies are micro firms that serve on average 9,000 patients with a staff of 8.7 full-time equivalents. In contrast with other studies on small firms that usually focus on firms up to 100 employees (e.g Sels et al. 2006), we study 'micro' firms (cf. Reid 1996) in which the entrepreneur is present at the work floor.

The paper is organized as follows: the next section discusses the literature on the effectiveness of HR systems and outlines the hypotheses of our research. Section 3 describes the data and variables used in this study and also discusses the models we estimated. The empirical results are presented in Section 4. Section 5 summarizes this study's conclusions and discusses its limitations. 


\section{Theoretical background and hypotheses}

In the literature on the effectiveness of HR practices, most authors focus on the effects of consistent 'HR systems', because there is a high degree of intercorrelation among specific HR practices (e.g. Arthur 1994; Ichniowski et al. 1997). The emerging literature on the effectiveness of HR systems particularly focuses on the internal fit of various HR practices. Ichniowski et al. (1997), for example, stated that in practice there is a hierarchy of HR systems from most 'traditional' to most 'innovative'. They first identified HR practices which are characteristic of the sector they analyze: the US steel industry. Then, they constructed four different HR systems by inspecting the distribution of the various HR practices in this sector of industry. In their analysis; they take account of HR practices in many different domains: incentive pay; recruitment and selection; teamwork; employment security; flexible job assignment; skills training; and communication. In this study, we will follow their approach and apply it to HR practices that are characteristic of the pharmacy sector in the Netherlands.

\section{Effects of HR systems}

In the HR literature, several arguments can be found for the expected positive relation between a firm's HR system and its productivity (cf. Wolf and Zwick 2002). First, investments in the quality of the workforce may increase the productivity of workers (e.g. Bartel 1994). Second, as the literature on the 'High Performance Workplace (HPW)' emphasizes, 'good' HR practices may increase the motivation of workers (Ichniowski et al. 1997; Wood 1999), and contribute to workers' commitment to their tasks and willingness to do a better job (Ichniowski et al. 1997). Batt (2002) supports the latter argument and relates it to the service sector. She finds that high commitment of the workforce contributes to the effectiveness of employee-customer interaction in service-sector firms. Third, giving more responsibility to the work floor enables the firm to delayer the organization by reducing middle management (Appelbaum, Berg, Bailey and Kalleberg 2000). Finally, good HR practices will reduce quit rates, which, in turn, decrease recruitment and selection costs, and increase the benefits of investments in firm-specific skills. Firms in service sectors in particular will benefit from these lower quit rates, since employee turnover in these sectors might induce customer turnover (Huselid 1995; Batt 2002).

Empirical evidence for the positive relationship between a firm's HR system and its productivity is not unobtrusive. Several studies showed that HR practices do have a positive effect on firms' productivity, although there usually is no clear effect attributable to specific HR practices (e.g. Ichniowski et al. 1997). Other studies, however, did not find unambiguous effects of HR systems or bundles of HR practices on productivity (e.g. Delaney and Huselid 1996). Most of these studies focus on large firms in the manufacturing sector, though. One may wonder whether the advantages of a more advanced HR system also hold for small or micro firms, which have no opportunities for delayering the organization, and for which it is difficult to introduce self-responsible teams that exclude the hierarchical position of the entrepreneur.

As mentioned, there are only a few studies on the effects of HR practices on firm performance that focus on small firms. In his study on small and medium-size US firms, Way (2002) observed hardly any effects of HPW practices on labour productivity. Zheng et al. (2006) showed a positive effect of 'motivational' practices on HR outcomes, such as staff turnover and staff competency, in Chinese SMEs. However, they did not find any impact of staff development on HR outcomes, and even negative effects of HR practices in the domain of social benefits. Faems et al. (2005) observed positive effects of some 'HR domains' on labour productivity but not on financial outcomes. This might indicate 
that HR practices in small firms are related to a higher capital intensity, and do not improve performance as such. Chandler and McEvoy (2000), however, found a positive effect of a more advanced HR system - defined as 'Total Quality Management' - on firm performance when supported by high training participation and group-based incentive compensation. However, it should be noted that their study refers to medium-size enterprises in manufacturing, which probably do not operate in local markets as most small firms in services do (cf. Ferligoj, Prasnikar and Jordan 1997). This is also true for Hayton (2004), who notes that he did not include firms with less than 100 employees because he did not expect these firms to have more advanced HR systems. Batt (2002) argued that more advanced HR practices do not pay off in small service-sector firms which work on local markets with a restricted scope of their market. Clearly, this argument also holds for the Dutch pharmacies we analyze in this paper.

As mentioned in the introduction, human resource management in Dutch pharmacies particularly focuses on improving the quality of the workforce. Therefore, our study also builds on the literature regarding training in small firms. Several studies showed that levels of training activity in SMEs are lower than in large firms (e.g. Lynch and Black 1998; Harris 1999; Storey 2004). Moreover, training participation in micro firms is lower than in larger SMEs (Hoque and Bacon 2006). According to Westhead and Storey (1997), the lower training activity in SMEs can be explained by their organizational constraints, such as lack of finance or time, the higher probability that trainees in small firms will be poached by other employers, the absence of internal labour markets, or because business owners are ignorant of the full benefits of training. In addition, smaller firms turn out to be more risk averse when allocating their resources for on-the-job training (Holtmann and Idson 1991).

Westhead and Storey (1997) did not find any convincing evidence of research which showed that the provision of training within small firms improves business performance (cf. Storey 2004). Patton, Marlow and Hannon (2000) argued that training activities in small firms should not be dealt with in isolation when analyzing its impact on firm performance (cf. Lynch and Black 1998). We therefore look at training activities in the context of HR systems. This is also in line with the notion in HRM literature that there is no clear effect on firm performance attributable to specific HR practices (e.g. Arthur 1994).

In addition to effects on firm productivity, more advanced HR practices may affect the employees involved. Osterman (2000) addressed the question of whether firms with a HPW are 'mutual gain enterprises' for employer and employees. He did not find any benefits of HPW practices for a firm's core workforce in terms of lower layoff rates and/or higher average real wage increases. In addition, Handel and Gittleman (2004) did not observe a positive effect of a HPW on workers' wages. Black and Lynch (2004) and Forth and Millward (2004), however, found that reengineering a workplace to incorporate high performance practices increases workers' wages. Moreover, Bauer and Bender (2001) showed that flattening the hierarchical structure of an establishment and introducing selfmanaged teams in particular affect employees' wages positively. In their overview study, Handel and Levine (2004) conclude that, although the evidence is mixed, the average effect of firms introducing more advanced HR practices is a small increase in employees' wages. However, it should be noted that none of the studies Handel and Levine (2004) discuss focuses on small or micro firms.

\section{Hypotheses}

As mentioned above, the more advanced HR systems used in Dutch pharmacies focus on improving the quality of the workforce by means of performance evaluation, permanent 
contracts, training, employing a highly competent workforce, and allowing assistants to perform tasks of the pharmacist. Can these more advanced HR systems improve the performance of pharmacies?

Evidently, an HR system that improves the quality of service might improve the competitiveness of a pharmacy. However, it is, above all, the study of Batt (2002) that makes us doubt whether a more advanced HR system will have a positive effect on the performance of small firms in the service sector that are operating on a restricted local market. Serving a local market, as pharmacies do, offers few opportunities to increase the level of sales by means of a more productive HR system that makes the firm more competitive. Therefore, these firms can only reap the benefits of a more productive HR system by reducing their workforce. Clearly, this will have a negative impact on employees' motivation and firm-loyalty, which will probably destroy any positive effect of a potentially more productive HR system. We thus expect that pharmacies will not be able to reap this potentially higher productivity. Moreover, like other small firms, pharmacies have no opportunities to flatten their organization, because they do not employ any middle management that can be reduced by increasing the autonomy of employees on the shop floor. Finally, pharmacies cannot benefit from the introduction of self-responsible teams, due to the professional authority and the hierarchical position of the pharmacist who usually is present on the shop floor. We, therefore, formulate the following hypothesis:

Hypothesis 1: The use of more advanced HR systems will not have a positive effect on the productivity of pharmacies.

As mentioned above, the evidence on the effects of the introduction of more advanced HR practices for employees is mixed. Handel and Levine (2004), however, conclude in their overview of the literature that the average effect is a small increase in employees' wages. Moreover, particularly in small firms, it can be expected that more formal HR practices will improve the bargaining position of employees, as an employer's discretionary power is usually very large in firms that apply a traditional HR system without any formal HR practices (e.g. Cahuc and Zylberberg 2004). Therefore, we formulate the following hypothesis:

Hypothesis 2: The use of more advanced HR systems will have a positive effect on workers' wages.

\section{Methodology}

\section{Data}

We employed a matched employer-employee data set, relating the data of an employers' survey we conducted among pharmacies in the Netherlands to administrative data on the workforce and the productivity of pharmacies. In the tradition of 'insider econometrics', we based this survey on extensive fieldwork to get a detailed understanding of the production process in Dutch pharmacies. In November 2001, a written questionnaire was mailed to 1,319 pharmacists 549 of whom responded. The response appeared to be unbiased with respect to region and pharmacy size. We were able to link the survey data with the available administrative data on pharmacies' productivity and with administrative pension fund data on workers' wages and other worker characteristics, such as workers' average age and tenure.

Table 1 shows means and standard deviations of the variables in the data set used. We will discuss these descriptive statistics in the remainder of this section. 
Table 1. Description of variables $(n=549)$.

\begin{tabular}{lrr}
\hline Variable & Mean & $\begin{array}{r}\text { Standard } \\
\text { deviation }\end{array}$ \\
\hline Wages and productivity & & \\
- Number of prescription lines per assistant per year $(\times 1,000)$ & 13.63 & 4.89 \\
- Assistants' average gross wages per month in euros $(\times 1,000)$ & 1.77 & .11 \\
HR practices & .75 & .43 \\
- Worker performance evaluation interview (yes/no) & .77 & .42 \\
- Percentage of assistants with temporary contracts lower than 20\% & .77 \\
- Assistants follow courses & .55 & .42 \\
- Assistants perform tasks of pharmacist & .43 & .50 \\
- Assistants' average score on skills higher than 7.5 & & \\
& & \\
Firm characteristics & .70 & .46 \\
- Type of pharmacy & .18 & .38 \\
- Independent (yes/no) & .13 & .33 \\
- Cooperation of less than 5 pharmacies (yes/no) & .53 & .50 \\
- Cooperation of 5 or more pharmacies (yes/no) & .17 & .37 \\
- More than 10 employees (yes/no) & .56 & .50 \\
- New computer system (yes/no) & & \\
Wrganizational changes (yes/no) & & \\
Workforce characteristics & 36.61 & 4.39 \\
- Assistants' average age in years & 6.89 & 2.73 \\
- Assistants' average job tenure in years & .05 & .08 \\
- Share of second pharmacists in total number of employees & .15 & .11 \\
\hline
\end{tabular}

\section{Performance measures: firms' productivity and workers' wages}

In studies on the effects of HR practices, various indicators of firm performance have been used: subjective measures of firm performance (Delaney and Huselid 1996; Zheng et al. 2006), financial measures such as firms' profits (e.g. Terpstra and Rozell 1993), total factor productivity (Chen, Liaw and Lee 2003) or Tobin's q, i.e. the ratio of a firm's market value to the replacement value of its assets (e.g. Huselid 1995), firms' value added or sales per employee (e.g. Black and Lynch 2001), innovations in products (Ferligoj et al. 1997), or physical measures of firms' productivity (e.g. Arthur 1994).

Physical measures of productivity can of course only be used in studies that focus on a particular industry (e.g. Arthur 1994; MacDuffie 1995). In such studies, physical measures of productivity have a clear advantage above other measures of firm performance, because they can be considered as relatively 'hard' data on the performance of a firm (Ichniowski et al. 1996), whereas measures of firm performance that are based on managers' perceptions may be biased both in the judgment of firm performance itself, and in the selection of the firm the manager chooses for benchmarking performance. Moreover, financial measures are affected by many systematic and ad hoc factors for which it is very difficult to control, whereas physical measures of productivity are straightforward in measuring productivity, given the specific production process in a sector of industry (cf. Ichniowski and Shaw 2003).

The administrative data enable us to use a physical measure of productivity: the number of prescription lines annually delivered to customers per full-time assistant. Each prescription line refers to a particular medicine delivered to a customer. Family doctors 
write these prescription lines, this being the only way in which registered medicines can be obtained in the Netherlands. The average number of prescription lines per assistant is a good indicator of the performance of a pharmacy, since it determines the quantity of medicines delivered to customers, whereas there are only minor differences in the workload between delivering different medicines. ${ }^{1}$ On average, a full-time assistant in a pharmacy handles 13,630 prescription lines per year.

In order to find out whether employees also benefit from more advanced HR practices in pharmacies, we look at their wages. Data from the pension fund were used to calculate assistants' average gross (full-time) monthly wages per pharmacy, which amounts to on average 1,770 euros per month.

\section{HR practices in Dutch pharmacies}

In contrast with most studies that focus on the effects of HR systems in large firms, we do not concentrate on the characteristics of a HPW, which is typical for a more advanced HR system in large firms (see e.g. Osterman 2000). Instead, we analyze the effects of HR systems that are characteristic of HR practices in Dutch pharmacies. From extensive field interviews, we learned that HR practices in Dutch pharmacies particularly focus on improving the quality of the workforce. For this purpose, pharmacies apply the more basic practices in the field of human resource development, such as performance interviews, training, and informal learning.

Pharmacists' assistants usually work in small teams that are managed by the pharmacist-owner or manager. In this team, pharmacist's assistants are the core employees that represent $80 \%$ of the total workforce. In most pharmacies, they are supported by lower level 'pharmacy helpers', who perform some basic tasks, and some part-time cleaning personnel and administrative staff. Moreover, some pharmacies employ a second pharmacist. Within a team, there usually is no hierarchical job structure for pharmacist's assistants. $^{2}$ Due to the flat organizational structure there are no opportunities for internal promotions to higher-level jobs. This makes pharmacists' assistants' jobs very characteristic of semi-professional craft markets, as has been put forward in the early literature on internal labor markets (Doeringer and Piore 1971). The pharmacist's assistant job is a registered health occupation with a formal job description. Only graduates from a pharmacist's assistants' vocational training program are allowed to be employed in the occupation.

Although pharmacies are micro firms, $75 \%$ of the Dutch pharmacies organize formal employee performance interviews (see Table 1). These interviews can be seen as a basic HR practice, which enable the pharmacist as well as the pharmacist's assistant to evaluate the performance of the assistant and to determine competencies for which the assistant has some emerging skill gaps. However, employee performance interviews also offer assistants a floor for bargaining on their own wage level. The latter holds even more when it is the pharmacist who wants the assistant to enrol in a particular course, for which the pharmacist's assistant wants to be rewarded.

Like most firms, pharmacies face a trade-off between the advantages of investments in their human resources and the need to be flexible in the size of their workforce (cf. Treu 1992; Arulampalam and Booth 1998). The latter found that workers with temporary contracts are significantly less likely to be involved in any work-related training. Moreover, there is a negative relation between investments in human resource development and labour turnover (Huselid 1995; Batt 2002). Pharmacies that are less inclined to invest in the quality of their workforce will therefore have more vacancies and 
employ more assistants with temporary contracts. On average, only $13 \%$ of pharmacist assistants have a temporary contract. In $77 \%$ of the pharmacies the percentage of assistants employed by means of a temporary contract is less than $20 \%$.

The pharmacy sector is characterized by rapid developments in the medicines available, and an increasing demand among customers for information about the characteristics and side effects of the drugs delivered. Therefore, it is highly important that pharmacists' assistants keep their knowledge on medicines up-to-date. For this reason, human resource development forms the heart of the HR practices in Dutch pharmacies. The data also show that pharmacists encourage their assistants to invest in skills. On average, assistants in $77 \%$ of the pharmacies enrol on courses. Apart from participation in formal courses, informal learning is an important way in which pharmacist's assistants develop their skills further. In this respect, it is of particular interest whether assistants are allowed to perform tasks that actually belong to the workload of the pharmacist, as these tasks enrich the job content of pharmacist's assistants to a large extent. Our survey shows that in $55 \%$ of the pharmacies one or more assistants are sometimes performing tasks of the pharmacist.

The skill level of pharmacist's assistants is to a large extent determined by the human resource development practices of the pharmacy. Since all assistants attended the same government required vocational education program, the skill level of the assistants in a pharmacy can be interpreted as the 'stock' of human resource development investments (cf. Lynch 1998), which indicates the value of accumulated HR practices during assistants' working careers. We asked the pharmacists to rate the average skill level of their assistants for 10 different skills. These skills refer to specific pharmaceutical competencies (knowledge of medicines, knowledge of syndromes, prescription of medicines, preparation of medicines, and giving information on use and side-effects of medicines) as well as general skills (communication skills, teamwork skills, being independent, dealing with responsibility, and computer skills). The skill scores refer to the score scales from 0 to 10 common in Dutch education, in which a score of 6 is a passing grade. In order to indicate whether a pharmacy employs high-quality employees, we distinguish between pharmacies with average skill scores below and above 7.5. In Dutch education this score is considered to be in between 'ample sufficient' (7) and 'good' (8). In $43 \%$ of the pharmacies the skill level of their assistants rated above 7.5.

\section{Human resource management systems}

To analyze the effects of a more advanced HR system on firms' productivity and workers' wages, we identify four HR systems that map out a hierarchy from a 'traditional' HR system to what we label as a 'High Quality' system, which focuses on developing a very competent workforce. We identified these four HR systems by following the approach of Ichniowski et al. (1997), which takes into account the actual use of more advanced HR practices in a specific sector of industry - in our case the Dutch pharmacy sector.

We first inspected the sample distribution of the various HR practices, and looked for natural breakpoints in the use of these practices. The four most common combinations of HR practices in the Dutch pharmacies are then labelled as a HR system. ${ }^{3}$ Table 2 describes the HR practices included in the four systems. In our approach, a pharmacy only has a more advanced HR system when it applies all HR practices related to this HR system.

The first HR system is the traditional HR system of personnel management in smaller firms. Here, no visible practices exist that focus on improving assistants' performance. $26 \%$ of the Dutch pharmacies belong to this group. The second HR system refers to a 
Table 2. Description of indicators included in the four HR systems distinguished.

\begin{tabular}{lc}
\hline & $\%$ \\
\hline HR system 1: Traditional HR system & 26 \\
- No HR practices that focus on improving performance & \\
HR system 2: Basic HR system & \\
- Worker performance evaluation interviews & 34 \\
HR system 3: Intermediate HR system & \\
- Worker performance evaluation interviews & \\
- Percentage of assistants with temporary contracts lower than 20\% & \\
- Assistants follow courses & \\
HR system 4: High quality HR system & \\
- Worker performance evaluation interviews & \\
- Percentage of assistants with temporary contracts lower than 20\% & \\
- Assistants follow courses & \\
- Assistants perform tasks of pharmacist &
\end{tabular}

basic HR system that merely incorporates the most often used HR practice of worker performance evaluation interviews, $28 \%$ of the pharmacies belong to this group. In the intermediate HR system (the third system) more HR practices are included that aim at improving the human capital and commitment of the workforce. Next to performance evaluation interviews, assistants in these pharmacies take courses to continually upgrade their knowledge and skills. Moreover, these pharmacies do not employ many assistants with temporary contracts. Workers with permanent contracts are usually more committed to their employing firm, because job security increases workers commitment for acquiring 'relation-specific' knowledge and skills (De Grip, Hoevenberg and Willems 1997; Crawford 1990). Of the Dutch pharmacies $34 \%$ belong to the group with an intermediate HR system.

The fourth HR system we distinguish is a High Quality HR system. Only $13 \%$ of the Dutch pharmacies have such a High Quality system. Apart from the HR practices incorporated in the third HR system, the High Quality system focuses on the development of high-performance assistants, i.e. assistants with an average skills score of 7.5 or higher. Moreover, in these pharmacies, (some) assistants perform tasks of the pharmacist.

It should be noted that we do not include variables on the presence of job rotation, selfresponsible teams, or quality circles in this High Quality HR system. As mentioned, these HPW practices are not relevant for Dutch pharmacies where all assistants work together in a small team without any hierarchy ${ }^{4}$ except for the role of the pharmacist who actually restrains the development of truly self-responsible teams.

\section{Control variables}

In our empirical analyses, we control for a number of firm characteristics, such as firm size and type of pharmacy. The majority of Dutch pharmacies (70\%) are independent pharmacies, run by a pharmacist who is the owner of the firm. The rest of the pharmacies cooperate with other pharmacies. By law, each pharmacy must have a universitygraduated pharmacist at the workplace who is responsible for the management of the pharmacy. It should be kept in mind that pharmacies in the Netherlands are not part of very large organizations with internal labor markets. ${ }^{5}$ We also include in our analysis whether 
the pharmacy recently introduced a new computer system or changes in the organization, as several studies show that technological and organizational innovations may contribute to higher levels of firm productivity (e.g. Bresnahan, Brynjolfsson and Hitt 2002), and may also result in an increase in workers' wages (Bauer and Bender 2001). During the survey year $17 \%$ of the pharmacies introduced a new computer system and $56 \%$ of the pharmacies experienced organizational changes such as a merger or reorganization.

Moreover, we control for a number of workforce characteristics that usually affect workers' wages and productivity: assistants' average age and job tenure. As shown in Table 1 pharmacists' assistants on average are 36.6 years old, and on average have tenure of about 7 years. Because all assistants attended the same legally required vocational training program, we do not include the pharmacists' assistants' educational background as a control variable in the analysis. Finally, we include control variables for other categories of workers in the pharmacies in our estimations on firm productivity.

\section{Econometric model}

To analyze the effects of different HR systems on workers' wages and the performance of the firm, we estimate two equations: ${ }^{6}$

$$
\begin{gathered}
\operatorname{In}(P / L)_{\mathrm{i}}=\alpha_{2}+\beta_{2}^{\prime} H R S_{\mathrm{i}}+\delta_{2}^{\prime} X_{\mathrm{i}}+\gamma_{2}^{\prime} \operatorname{In}(Z / L)_{\mathrm{i}}+\varepsilon_{2 \mathrm{i}} \\
\operatorname{In}(W / L)_{\mathrm{i}}=\alpha_{1}+\beta_{1}^{\prime} H R S_{\mathrm{i}}+\delta_{1}^{\prime} X_{\mathrm{i}}+\varepsilon_{1 \mathrm{i}}
\end{gathered}
$$

$P_{\mathrm{i}}=$ number of prescription lines delivered in firm i; $L_{\mathrm{i}}=$ number of assistants (in fulltime equivalents) in firm i; $W_{\mathrm{i}}=$ total wages of pharmacist's assistants in firm i; $H R S_{\mathrm{i}}=$ Human Resource System in firm i; $X_{\mathrm{i}}=$ control variables; $Z_{\mathrm{i}}=$ additional staff; $\alpha, \beta^{\prime}, \delta^{\prime}$, $\gamma^{\prime}=$ (vectors of) coefficients; $\varepsilon_{1 \mathrm{i}}, \varepsilon_{2 \mathrm{i}}=$ error terms.

The first equation is a production function in which we estimate the effects of different HR systems on the firm's productivity assuming constant returns to scale (cf. Black and Lynch 2001). As mentioned above, we measure firm productivity by the average number of prescription lines delivered by pharmacist's assistants to the firm's customers. In the second equation, we analyze the effects of HR systems on the pharmacist's assistants' wage level. This indicates the extent to which assistants benefit from the firm's HR system. Moreover, we include the control variables related to firm and workforce characteristics mentioned. These controls differ between the two equations, since in equation 1 we have to add additional controls for the other categories of workers in pharmacies (cf. Black and Lynch 2001), i.e. the ratio between other staff employed and pharmacists' assistants. In order to impose constant returns to scale, we take the log transformation of the latter term.

\section{Results}

Table 3 shows the estimation results of the two equations, which confirm our first hypothesis. As expected, pharmacies with a more advanced HR system do not experience higher productivity. Assistants, however, do benefit from more advanced HR systems by means of higher wages. This confirms the second hypothesis. Our estimation results show that, with respect to workers' wages, there actually are two significant steps in the development towards a High Quality HR system. The introduction of worker performance evaluation interviews is a first step that increases workers' wages. However, assistants benefit most from a High Quality HR system. The introduction of an intermediate HR system does not add any value to the basic HR system, however. These results indicate that 
Table 3. Estimation results: the effects of HRM systems on firms' productivity and workers' wages.

\begin{tabular}{|c|c|c|c|c|}
\hline \multirow[b]{2}{*}{ Variable } & \multicolumn{2}{|c|}{$\begin{array}{l}\text { Prescription } \\
\text { lines }(\ln )\end{array}$} & \multicolumn{2}{|c|}{$\begin{array}{l}\text { Average wage } \\
\text { level }(\ln )\end{array}$} \\
\hline & $B$ & $t$-value & $B$ & $t$-value \\
\hline $\begin{array}{l}\text { Constant } \\
\text { HR system }\end{array}$ & \multicolumn{4}{|c|}{ HR system } \\
\hline - HR system 1 - Traditional system (ref.) & - & - & - & - \\
\hline - HR system 2 - Basic system & -.003 & -.38 & $.020 * *$ & 3.03 \\
\hline - HR system 3 - Intermediate system & .002 & -.53 & .007 & 1.47 \\
\hline - HR system 4 - High Quality system & .038 & 1.26 & $.020 * *$ & 2.44 \\
\hline \multicolumn{5}{|l|}{ Firm characteristics } \\
\hline - New computer system (yes/no) & -.028 & -0.89 & .005 & .80 \\
\hline - Organizational changes (yes/no) & .024 & 1.06 & .009 & 1.37 \\
\hline $\begin{array}{l}\text { - Type of pharmacy } \\
\text { - Independent (yes/no) }\end{array}$ & 05 & & 00 & 2 \\
\hline - Cooperation of less than 5 pharmacies (yes/no) & -.013 & -.155 & $.020 * *$ & 1.96 \\
\hline - Cooperation of 5 or more pharmacies (ref.) & - & - & - & - \\
\hline - More than 10 employees (yes/no) & $-.133 * * *$ & -3.42 & $.010 *$ & 1.59 \\
\hline \multicolumn{5}{|l|}{ Workforce characteristics } \\
\hline - Assistants' average age in years & .001 & .43 & $.007 * * *$ & 9.08 \\
\hline - Assistants' average job tenure in years & .001 & -.46 & $.004 * * *$ & 3.62 \\
\hline - Employment ratio of second pharmacists (ln) & $.027 * * *$ & 3.50 & - & - \\
\hline - Employment ratio of other employees (ln) & $.019 * *$ & 2.34 & - & - \\
\hline Adjusted $\mathrm{R}^{2}$ & .10 & & .36 & \\
\hline $\mathrm{n}$ & 377 & & 377 & \\
\hline
\end{tabular}

$* \mathrm{p}<0.10 ; * * \mathrm{p}<0.05 ; * * * \mathrm{p}<0.01$.

both introducing a basic HR system and a High Quality HR system have different effects for assistants and the pharmacy that employs them, as we expected in the hypotheses formulated in section 2. However, this does not hold for the intermediate HR system.

It should be noted that the lack of any effects of more advanced HR systems on firms' productivity may also be due to time lags between the implementation of a more advanced HR system, and any subsequent change in firm performance (Huselid and Becker 1996). When pharmacies introduced particular HR practices quite recently, our estimation results might underestimate the effect on firms' productivity. Unfortunately, we have no data on the timing of the introduction of the HR practices. However, it is remarkable that we find that workers benefit from a more advanced HR system without any delay.

Since the data we used are cross-sectional, our estimation results might also suffer from a selectivity effect for which we could not control. As shown by Wolf and Zwick (2002), a negative selectivity effect may occur because less productive firms have an incentive to introduce a more productive HR strategy. Our regression results may therefore underestimate the effects of a more advanced HR system on firm performance. However, this also holds for the studies on large firms mentioned earlier. Using cross-sectional data, they find a positive relation between HR systems and firm performance.

With respect to the control variables we included in our analysis, we do not find any significant effects of the introduction of new computer systems or organizational changes on firm productivity or assistants' wages. Moreover, we observe negative economies of 
scale on firm productivity, but a slightly positive relationship between organizational size and workers' wages. Finally, we find that average wages are significantly related to the assistants' average age and job tenure (cf. De Grip and Sieben 2005). This, however, is not reflected in a higher average firm productivity.

\section{Conclusion and discussion}

In this study, we analyzed the effects of non-traditional HR systems on the performance of Dutch pharmacies, which are micro firms that operate on a local market. In contrast with more advanced HR systems in large firms, pharmacies with a High Quality HR system do not have HR practices such as job rotation, self-responsible teams, or quality circles. Instead, they focus on improving the quality of the workforce by means of performance evaluation, permanent contracts, training, employing a highly competent workforce, and allowing assistants to perform tasks of the pharmacist. We, therefore, distinguish four HR systems: (1) a traditional HR system without any visible HR practices, which aims at improving the performance of pharmacists' assistants; (2) a basic, more formal, HR system with worker performance evaluation interviews; (3) an intermediate HR system; and (4) a High Quality HR system.

We found that workers indeed benefit from more advanced HR systems as they receive higher wages. This finding can be explained by our expectation that the introduction of a basic more formal HR system will improve the bargaining position of employees who are employed in small firms, whereas in a traditional HR system without any formal HR practices, the pharmacist-entrepreneur can operate relatively autocratically. Moreover, employee performance interviews offer assistants a floor for bargaining on their own wage level regularly. Our finding, that employees benefit from a more advanced 'High Quality' HR system, shows that firms reward the higher quality of their workforce. In this respect, it is interesting that we did not find any positive effect of the intermediate HR system on employees' wages. Actually, this intermediate HR system, which is applied by about one third of all Dutch pharmacies, seems to balance employees' interest with the pharmacists' interest. It should be noted that in this intermediate HR system - as opposed to the High Quality HR system - the pharmacist evidently is the dominant expert in the organization, as his or her tasks are not taken over by very competent assistants.

Second, we found that more advanced HR systems do not have any effect on firms' productivity, as is often observed in large firms. This finding can be explained by the fact that pharmacies are micro firms that serve a local market. A local market hardly offers any opportunities to increase the sales by means of a more advanced HR system (cf. Batt 2002). Therefore, pharmacies can only reap the benefits of a more productive HR system when they lay-off some of their employees. However, when they do this, they will obviously lose the loyalty or their employees, which is essential to make a more advanced HR system productive. Moreover, small firms have no possibilities to benefit from flattening the organization, which is one of the reasons why a more advanced HR system might increase productivity in large firms (Appelbaum et al. 2000). In addition, it is very difficult to create a real HPW in a pharmacy setting. Although assistants are professionals who usually work in a team, the pharmacist will not only act as a manager, but also is the 'dominant' professional. Therefore, although pharmacists' assistants obviously do not have 'Taylorist jobs', their autonomy will always be to some extent restricted by both the professional authority and the hierarchal position of the pharmacist.

A more general explanation for our finding that the productivity of pharmacies does not improve by implementing a more advanced HR system might be that in small or micro 
firms, formal HR practices are less important for workers' productivity levels than personal relations between the employer and his or her employees (cf. Bacon and Hoque 2005). This is in line with conclusions of Guest (1999), who states that small firms have less need to adopt specific HR systems that aim at maximizing employees' commitment, since this already is at a higher level than in large firms.

\section{Acknowledgements}

We would like to thank Ben Kriechel, Wendy Smits and Danielle Van Jaarsveld for helpful comments on an earlier draft of this article.

\section{Notes}

1. Moreover, it should be noted that in the Netherlands non-registered medicines are almost always bought in commercial drugstores and hardly contribute to the sales of pharmacies.

2. More recently, a new job classification system was introduced, which distinguishes between standard jobs for pharmacists' assistants and three higher level specializations: pharmaceutical client care; coordination; and quality management.

3. This approach differs from the 'additive index' definition of HR systems (Wood 1999) as the latter approach allows different combinations of HR practices to be involved in more advanced HR systems. The additive index approach probably is more suitable in studies that cover different sectors of industry, whereas our approach makes it possible to take account of the actual use of more advanced HR practices in a particular sector of industry.

4. As mentioned above, pharmacists' assistants are supported by: lower level 'pharmacy helpers', who perform some basic tasks; some part-time cleaning personnel; and administrative staff. However, our analysis focuses on the pharmacist's assistants who are the core workers of the pharmacies.

5. Our estimation results do not substantially change when we exclude, from our analyses, pharmacies which cooperate with other pharmacies.

6. We estimate these two equations as a set of 'seemingly unrelated regression equations' (Zellner 1962). By using EGLS estimators, we are able to use the information on the explanatory variables that are only included in the second equation when estimating the first equation and allow for correlation between the two error terms.

\section{References}

Appelbaum, E., Berg, P., Bailey, T., and Kalleberg, A.L. (2000), Manufacturing Advantage. Why High-performance Systems Pay Off, Ithaca, NY: ILR Press.

Arthur, J.B. (1994), 'Effects of Human Resource Systems on Manufacturing Performance and Turnover,' Academy of Management Journal, 37, 670-687.

Arulampalam, W., and Booth, A.L. (1998), 'Training and Labour Market Flexibility: Is There a Trade-off?,' British Journal of Industrial Relations, 36, 521-536.

Bacon, N., and Hoque, K. (2005), 'HRM in the SME Sector: Valuable Employees and Coercive Networks,' The International Journal of Human Resource Management, 16, 1976-1999.

Bartel, A.P. (1994), 'Productivity Gains from the Implementation of Employee Training Programs,' Industrial Relations, 33, 411-425.

Batt, R. (2002), 'Managing Customer Services: Human Resource Practices, Quit Rates, and Sales Growth,' Academy of Management Journal, 45, 587-597.

Bauer, T.K., and Bender, S. (2001), Flexible Work Systems and the Structure of Wages: Evidence from Matched Employer-Employee Data, Bonn: IZA Discussion Paper No. 353.

Black, S.E., and Lynch, L.M. (2001), 'How to Compete: The Impact of Workplace Practices and Information Technology on Productivity,' The Review of Economics and Statistics, 83, 434-445.

Black, S.E., and Lynch, L.M. (2004), 'What's Driving the New Economy: The Benefits of Workplace Innovation,' Economic Journal, 114, F 97-F 116.

Bresnahan, T.F., Brynjolfsson, E., and Hitt, L.M. (2002), 'Information Technology, Workplace Organization and the Demand for Skilled Labor: Firm-level Evidence,' Quarterly Journal of Economics, 116, 1449-1492. 
Cahuc, P., and Zylberberg, A. (2004), Labor Economics, Cambridge, MA: MIT Press.

Chandler, G.N., and McEvoy, G.M. (2000), 'Human Resource Management, TQM, and Firm Performance in Small and Medium-size Enterprises,' Entrepreneurship Theory and Practice, $25,43-57$.

Chen, L.-H., Liaw, S.-Y., and Lee, T.-Z. (2003), 'Using an HRM Pattern Approach to Examine the Productivity of Manufacturing Firms - An Empirical Study,' International Journal of Manpower, 24, 299-318.

Crawford, V.P. (1990), 'Relation-specific Investment,' Quarterly Journal of Economics, 105, $561-574$.

De Grip, A., Hoevenberg, J., and Willems, E. (1997), 'Atypical Employment in the European Union,' International Labour Review, 136, 49-71.

De Grip, A., and Sieben, I. (2005), 'The Effects of Human Resource Management on Small Firms' Productivity and Employees' Wages,' Applied Economics, 37, 1047-1054.

De Kok, J.M.P., and Uhlaner, L.M. (2001), 'Organizational Context and Human Resource Management in the Small Firm,' Small Business Economics, 17, 173-291.

Delaney, J.T., and Huselid, M.A. (1996), 'The Impact of Human Resource Management Practices on Perceptions of Organizational Performance,' Academy of Management Journal, 39, 949-969.

Doeringer, P.B., and Piore, M.J. (1971), Internal Labor Markets and Manpower Analysis, Lexington, MA: Heath Lexington Books.

Faems, D., Sels, L., De Winne, S., and Maes, J. (2005), 'The Effect of Individual HR Domains on Financial Performance: Evidence from Belgian Small Businesses,' International Journal of Human Resource Management, 16, 676-700.

Ferligoj, A., Prasnikar, J., and Jordan, V. (1997), 'Competitive Advantage and Human Resource Management in SMEs in a Transitional Economy,' Small Business Economics, 9, 503-514.

Forth, J., and Millward, N. (2004), 'High-involvement Management and Pay in Britain,' Industrial Relations, 43, 98-119.

Geroski, P.A. (2000), 'Models of Technology Diffusion,' Research Policy, 29, 603-625.

Guest, D.E. (1999), 'Human Resource Management: The Workers' Verdict,' Human Resource Management Journal, 9, 5-25.

Handel, M.J., and Gittleman, M. (2004), 'Is There a Wage Pay-off to Innovative Work Practices?,' Industrial Relations, 43, 67-97.

Handel, M.J., and Levine, D.I. (2004), 'Editors' Introduction: The Effect of New Work Practices on Workers,' Industrial Relations, 43, 1-43.

Harris, R.I.D. (1999), 'The Determinants of Work-related Training in Britain in 1995 and the Implications of Employer Size,' Applied Economics, 31, 451-463.

Hayton, J.C. (2004), 'Strategic Human Capital Management in SMEs: An Empirical Study of Entrepreneurial Performance,' Human Resource Management, 42, 375-391.

Heneman, R.L., Tansky, J.W., and Camp, S.M. (2000), 'Human Resource Management Practices in Small and Medium-sized Enterprises: Unanswered Questions and Future Research Perspectives,' Enterprise Theory and Practice, 25, 11-26.

Holtmann, A.G., and Idson, T.L. (1991), 'Employer Size and On-the-job Training Decision,' Southern Economic Journal, 58, 339-355.

Hoque, K., and Bacon, N. (2006), 'The Antecedents of Training Activity in British Small and Medium-sized Enterprises,' Work Employment \& Society, 20, 531-552.

Hornsby, J.S., and Karatko, D.K. (1990), 'Human Resource Management in Small Business: Critical Issues for the 1990s,' Journal of Small Business Management, 28, 9-18.

Huselid, M.A. (1995), 'The Impact of Human Resource Management Practices on Turnover, Productivity, and Corporate Financial Performance,' Academy of Management Journal, 38, $635-672$.

Huselid, M.A., and Becker, B.E. (1996), 'Methodological Issues in Cross-sectional and Panel Estimates of the Human Resource-firm Performance Link,' Industrial Relations, 35, 400-422.

Ichniowski, C., Kochan, T.A., Levine, D., Olson, C., and Strauss, G. (1996), 'What Works at Work: Overview and Assessment,' Industrial Relations, 35, 299-333.

Ichniowski, C., and Shaw, K. (2003), 'Beyond Incentive Pay: Insiders' Estimates of the Value of Complementary Human Resource Management Practices,' Journal of Economic Perspectives, 17, 155-180. 
Ichniowski, C., Shaw, K., and Prennushi, G. (1997), 'The Effects of Human Resource Management Practices on Productivity: A Study of Steel Finishing Lines,' American Economic Review, 87, $291-312$.

Lynch, L.M. (1998), 'A Needs Analysis of Training Data: What Do We Want, What Do We Have, Can We Ever Get It?,' in Labor Statistics Measurement Issues, eds. J. Haltiwanger, M.E. Manser and R. Topel, Chicago, IL: University of Chicago Press, pp. 405-426.

Lynch, L.M., and Black, S.E. (1998), 'Beyond the Incidence of Employer Provided Training,' Industrial and Labor Relations Review, 52, 64-81.

MacDuffie, J.P. (1995), 'Human Resource Bundles and Manufacturing Performance: Organizational Logic and Flexible Production Systems in the World Auto Industry,' Industrial and Labor Relations Review, 48, 197-221.

Milgrom, P., and Roberts, J. (1995), 'Complementarities and Fit Strategy, Structure, and Organizational Change in Manufacturing,' Journal of Accounting and Economics, 19, 179-208.

Osterman, P. (1994), 'How Common is Workplace Transformation and Who Adopts It?' Industrial and Labor Relations Review, 47, 173-188.

Osterman, P. (2000), 'Work Reorganization in an Era of Restructuring: Trends in Diffusion and Effects on Employee Welfare,' Industrial and Labor Relations Review, 53, 179-196.

Patton, D., Marlow, S., and Hannon, P. (2000), 'The Relationship between Training and Small Firm Performance; Research Frameworks and Lost Quests,' International Small Business Journal, 19, $11-27$.

Reid, G.C. (1996), 'Mature Micro-firms and their Experience of Funding Shortages,' Small Business Economics, 8, 27-37.

Sels, L., De Winne, S., Maes, J., Delmotte, J., Faems, D., and Forrier, A. (2006), 'Unravelling the HRM-Performance Link: Value-creating and Cost-increasing Effects of Small Business HRM,' Journal of Management Studies, 43, 319-342.

Storey, D.J. (2004), 'Exploring the Link, Among Small Firms, between Management Training and Firm Performance: A Comparison between the UK and other OECD Countries,' International Journal of Human Resource Management, 15, 112-130.

Terpstra, D., and Rozell, E. (1993), 'The Relationship of Staffing Practices to Organizational Level Measures of Performance,' Personnel Psychology, 46, 27-48.

Treu, T. (1992), 'Labour Flexibility in Europe,' International Labour Review, 31, 497-512.

Way, S.A. (2002), 'High Performance Work Systems and Intermediate Indicators of Firm Performance within the US Small Business Sector,' Journal of Management, 28, 765-785.

Westhead, P., and Storey, D.J. (1997), 'Training Provision and the Development of Small and Medium-sized Enterprises,' Research Report RR26, London: DfEE.

Wolf, E., and Zwick, T. (2002), 'Reassessing the Impact of High Performance Workplaces,' Discussion Paper No. 02-07, Mannheim: ZEW.

Wood, S. (1999), 'Human Resource Management and Performance,' International Journal of Management Reviews, 1, 367-413.

Zellner, A. (1962), 'An Efficient Method of Estimating Seemingly Unrelated Regressions and Tests of Aggregation Bias,' Journal of the American Statistical Association, 57, 348-368.

Zheng, C., Morrison, M., and O’Neill, G. (2006), 'An Empirical Study of High Performance HRM Practices in Chinese SMEs,' The International Journal of Human Resource Management, 17, $1772-1803$. 